\title{
Rasgos y singularidades del mercado digital de la información: redes sociales y cibermedios
}

\author{
Mercedes Zamarra, Universidad Complutense de Madrid, España
}

\begin{abstract}
Resumen: El mercado digital ha abierto muchas puertas a un extenso número de sectores. Las posibilidades de comercio que ofrece Internet son muy amplias y se han beneficiado de ello todas las ramas y servicios. Pero si un mercado se ha visto beneficiado en especial por la llegada del comercio en la red, ése es el de la información. En este trabajo nos proponemos hablar sobre las características que tiene el mercado digital de la información, analizar las raíces y la implantación de los medios de comunicación digitales y la revolución que se ha logrado con ello. El trabajo que exponemos, es parte del resultado del amplio estudio realizado como miembro del grupo de investigación "Cybermedia II: Desarrollos e Innovaciones del Periodismo en las Redes Sociales, en Internet y Telefonía Móvil. Convergencias, Modelos de Negocios, Servicio y Formación (Ref. CSO2011-25235) (Plan Nacional de I+D+i 2012-2014)”. En concreto sobre las sinergias periodísticas entre los medios, cibermedios y redes sociales. En el ponemos de manifiesto las aportaciones de las tecnologías de la información y la comunicación que han permitido un desarrollo de las capacidades comunicativas de los medios. La fusión de todos los formatos ha hecho evolucionar la comunicación de un modo espectacular, posibilitando al público obtener una comunicación hasta ahora imposible de lograr. Nuestro análisis de los medios más relevantes del panorama mediático español pone en evidencia esas sinergias, ese cambio y la importancia de las nuevas herramientas sociales, que continúan acercando aún más al público y a los medios.
\end{abstract}

Palabras clave: medios, cibermedios, redes sociales, sinergias, internet

\begin{abstract}
The digital market has opened many doors to a large number of sectors. Trade possibilities offered by the Internet are very spacious and have benefited from it all branches and services. But if a market has seen particularly benefited by the arrival of trade on the net, that's the information. In this paper we propose to discuss the features that the digital information market, analyze the roots and the implementation of digital media and the revolution has been achieved with it. The work we present is part of the result of extensive study as a member of the research group "Cybermedia II: Development and Innovations in Journalism Social Media, Internet and Mobile Telephony. Convergences, Business Models, Service and Training (Ref. CSO2011 25235) (National $R+D+i$ 2012-2014)" .Specifically on journalistic synergies between media, online media and social networks. In we show the contributions of information technology and communication that have allowed development of communication media capabilities. Merging all formats has evolved communication in spectacular fashion, allowing the public to obtain a communication hitherto impossible. Our analysis of the most relevant Spanish media landscape media highlights such synergies, that change and the importance of new social tools, which continue even closer to the public and the media.
\end{abstract}

Keywords: Media, Online Media, Social Networking, Synergies, Internet

\section{Introducción}

$\mathrm{E}$ 1 ciberperiodismo no es algo coyuntural ni pasajero. Es un nuevo modo de trabajar en comunicación, que se añade -y en ocasiones, sustituye- al periodismo tradicional. Lo complemente o lo reemplace, ni para los grupos de comunicación ni para las empresas particulares es una opción, sino una realidad ineludible, no solo por razones de competencia, sino por las grandes ventajas que supone contar con un canal que permite un contacto tan directo e inmediato con la audiencia y que, además, permite diversificar y rentabilizar esfuerzos con tanta eficacia.

Ello hace que en el mundo entero haya dejado de ser un fenómeno novedoso para convertirse en una forma de trabajo cotidiana. Tanto, que en muchos casos empieza a ser difícil distinguir a los medios de comunicación de las variantes digitales (webs, correo electrónico, chats, wikis, blogs) en cuanto a su eficacia y su alcance social en la transmisión de noticias y opiniones. Los ciberperiódi-

Revista Internacional de Tecnología, Ciencia y Sociedad

Volumen 4, Número 1, <http://tecnociencia-sociedad.com>, ISSN 2530-4895

(C) Global Knowledge Academics. Mercedes Zamarra

Todos los Derechos Reservados Permisos: soporte@gkacademics.com

Republicado de Revista Internacional de Tecnología, Conocimiento y Sociedad 4(2), 2015 (pp. 145-156) 
cos, la ciberradio y la cibertelevisión, acompañados por la telefonía móvil, ya están instalados como medios tan sólidos como lo fueron y siguen siendo los periódicos y revistas de papel.

Las redes sociales suponen un nuevo modo de comunicación interpersonal que aproxima a millones de usuarios bajo redes comunes, poniéndolos en contacto. Algo que han aprovechado los medios, para estar presente e intentar encontrar ahí un público dinámico. Las redes sociales, no son medios de por sí, son los medios los que la utilizan para sus diferentes objetivos: destacar noticias, poner en contacto a los usuarios con el medios, encuestas, preguntas, subir vídeos, fotos, sonidos, o simplemente una manera de buscar audiencia y con ella la publicidad.

En nuestro análisis del panorama mediático, es obvia esa relevancia de las redes sociales. Son una característica fundamental para los medios de comunicación, para los que ha cambiado su forma de trabajar y que probablemente lo haya hecho para siempre. Otro avance más que seguramente en poco tiempo quede corto ante los constantes desarrollos de las tecnologías de la información y la comunicación.

Así, nos encontramos que la mayor parte de las empresas intentan atraer usuarios hacia sus plataformas convencionales sirviéndose de las webs y las redes sociales. Para ello, Facebook o Twitter son ideales, puesto que permiten a los medios crear perfiles desde los que difundir las bondades de sus webs o promocionar sus contenidos en radio, periódicos impresos o televisión. Incluso, hay algunos que crean redes sociales propias dentro de sus webs.

\section{Metodología}

Las fuentes que hemos empleado para documentarnos sobre este campo son extensas, pero en especial hemos acudido al lugar que ocupa el centro de ese trabajo, Internet. Con este trabajo queremos destacar cuales son los principales rasgos y singularidades del mercado digital de la información, las sinergias periodísticas entre las redes sociales, y los cibermedios, desde el nuevo marco del mercado digital, las principales transformaciones en el mercado de la información y las características del nuevo consumidor digital.

El impulso tecnológico ha generado transformaciones en el mercado de la información/comunicación; entre otros, el enorme incremento del consumo de medios y los nuevos momentos y lugares de exposición, además de la aparición de un nuevo usuario que interactúa con la marca como nunca antes lo había hecho.

Se elige la prensa escrita para desarrollar el trabajo, ya que ésta es considerada el primer medio de comunicación en dar el gran salto al ciberespacio en comparación con otros medios como la radio o la televisión. El objetivo es analizar y observar las plataformas digitales en las redes sociales de los dos cibermedios generalista (El País y El Mundo) que tienen mayor presencia en la red española y su manera de comunicarse así como las herramientas de interacción que ofrecen para promover la participación del usuario en sus contenidos noticiosos.

\section{Los cibermedios en las redes sociales}

\section{El País, uno de los pioneros}

El País es uno de los periódicos que ha optado con mayor ahínco por esta remodelación de la prensa escrita, incorporando a su medio web, diferentes herramientas que generen contenidos y doten al periódico de características de las que antes carecía.

Uno de estos elementos es el "está pasando" que, otorga la inmediatez a la información que siempre ha faltado en los periódicos tradicionales. El periódico on-line ofrece un plus infinito de espacio para el almacenamiento de información, característica que se ha sabido aprovechar creando ficheros por noticias. Con el mismo objetivo se pone a disposición una hemeroteca en la que pueden consultarse todas sus ediciones, bien en versión escrita u on-line.

Para este acercamiento de los usuarios al tradicional medio escrito, ha incorporado recientemente un "Kiosko y Más", versión digital del quiosco tradicional, en el que el usuario puede suscri- 
birse y recibir el periódico todos los días en su aplicación correspondiente. Esta venta se ofrece con un precio menor al que requiere el periódico impreso -y la modalidad de suscripción total (papel + digital), suscripción digital, suscripción fin de semana-. Los precios oscilan desde 9,99 euros el mes hasta 99,99 euros al año.

Asimismo, con el fin de facilitar el acceso al periódico, ha añadido a su página web la opción de consultar el periódico desde cualquier dispositivo con acceso a internet, ya sea el tradicional ordenador, móvil, tablet, e-book, PlayStation, etc.

Por otra parte, para fomentar la participación y la interactividad del usuario con el periódico, ha creado diferentes herramientas, pasando así del modelo de comunicación lineal y unidireccional de la prensa impresa a un modelo multiactivo en el que se requiere la participación del lector, estableciendo así un usuario, que pueda y quiera participar en el periódico. También ofrece la posibilidad de entrevistas o chats on-line con diferentes personalidades. Esta forma de participación permite al lector poder preguntar al entrevistado lo que realmente le interesa saber y poder "hablar" relativamente con esa persona.

Una forma de interacción y colaboración con el medio se abre con la posibilidad que se ofrece de comentar cada una de las noticias que se han publicado. Se otorga de este modo al público la capacidad de poder mostrar su opinión libremente propiciando así una interactividad muy beneficiosa para el medio, que conoce las opiniones y los pareceres de sus lectores, y para el usuario, que encuentra una vía de canalización de sus pensamientos al leer las noticias. Asimismo se han creado foros, en los que se pueden comentar y debatir las noticias y los temas de candente actualidad, ofreciendo la posibilidad de intercambiar opiniones con personas que no sean estrictamente del entorno de cada uno.

Cuenta con un espacio propio en la portada de elpais.com, con un canal de "Última Hora" donde los profesionales dan a conocer la actualidad a tiempo real. Para finalizar, cabe añadir que también este periódico cuenta con su propio servicio RSS para ofrecer al lector los titulares más importantes en el momento en el que se produzcan. El esfuerzo por adaptarse al medio digital es evidente, desde la página principal se puede acceder a sub-secciones sobre internet, redes sociales, o dedicadas únicamente a Facebook o Twitter.

Tabla 1.1: elpais.com

\begin{tabular}{|l|l|r|}
\hline \multicolumn{1}{|c|}{ Página web } & \multicolumn{1}{|c|}{ http://elpais.com/ } & Seguidores \\
\hline Estructura de red social & Sí & \\
\cline { 1 - 2 } $\begin{array}{l}\text { Log In con cuentas de otras } \\
\text { redes sociales }\end{array}$ & Eskup (creada para el propio medio) & \\
\hline Página/Grupo/Perfil de Facebook & http://www.facebook.com/elpais & \multirow{2}{*}{2.751 .075} \\
\hline Perfil de Twitter & @el_pais & \\
\hline Promoción de artículos en redes & Facebook, Twitter, Google +, Eskup, Tuenti. & \\
\hline Gadgets en la web & Facebook, Twitter, Google + & \\
\cline { 1 - 2 } Redes sociales complementarias & Eskup & \\
\hline Agregadores de noticias & Menéame & \\
\hline Otras consideraciones & $\begin{array}{l}\text { En el perfil de twitter, cada sección (cultura, } \\
\text { internacional etc.) tiene su propio twitter, } \\
\text { que se suman al timeline de El País. }\end{array}$ & \\
\hline
\end{tabular}

Fuente: Elaboración propia, 2013.

\section{Presencia en las redes sociales}

Cuenta con una gran presencia en Facebook a través de su página, la cual se acerca a los 250.000 usuarios. Entre los contenidos, destacan los propios para la red social donde los lectores pueden dar su punto de vista. Tiene una presencia notoria de la red social, no sólo a través de links a la página, que se retroalimentan constantemente sino dando la posibilidad de recomendar todas las noticias 
que se redactan para la web. También es usado para mostrar diariamente las portadas de la edición impresa del diario y las tiras cómicas de sus dibujantes.

En Facebook solo tiene una cuenta principal y una por cada uno de sus suplementos. Al no ser una cuenta personal, sino una simple página dentro de Facebook, esta no tiene seguidores "amigos" por lo que la contabilización del impacto en los usuarios es más difícil de conocer que en Twitter, sin embargo Facebook tiene un sistema para conocer los intereses individuales de los usuarios basado en el botón "me gusta".

Facebook es utilizado de cara a ofrecer un tratamiento más especializado y orientado hacia lo visual con la subida continua de imágenes -fotos de actualidad, viñetas cómicas, portadas, etc...--

Las actualizaciones en Facebook no son tan numerosas como en Twitter, si bien tiene una interfaz más intuitiva que permite una breve visualización de la noticia a la que se accede por el link siempre a elpaís.com- con una imagen que la ilustra y una porción del texto de la misma

En Twitter hace mucho hincapié, su cuenta principal llega casi a dos millones ochocientos mil seguidores de 23 países y 75 ciudades (la mayor parte está interesado en Marketing, Social Media, Digital, Community), y se mantiene continuamente activa actualizándose a un ritmo de al menos dos mensajes por hora, con una media de 53 tweets por día, 7.662 retweets por 100 tweets. Su perfil tiene 75 respuestas por 100 tweets, además comparte 290 links a la semana.

Hay que señalar que tiene en su web muchos enlaces que nos llevan a esta red social, prueba de ello es el altísimo número de seguidores. Todas las noticias tienen la posibilidad de poder seguirlas a través de esta herramienta.

En el seguimiento que hicimos durante una semana -del 18 al 24 de junio- a través de "Tweet Reach" nos permitió medir el alcance que tuvo la cuenta de Twitter, las observaciones realizadas mediante intervalos de cinco minutos, nos dio unos 30 tweets publicados por el medio, con 15 retweets y 5 comentarios. Alcance estimado de 54.093, la exposición, (impresiones) 61.132. Esto da lugar a un aumento de los seguidores del medio, claro beneficio y de la participación de los usuarios.

Figura 1: Datos seguimiento Tweet Reach

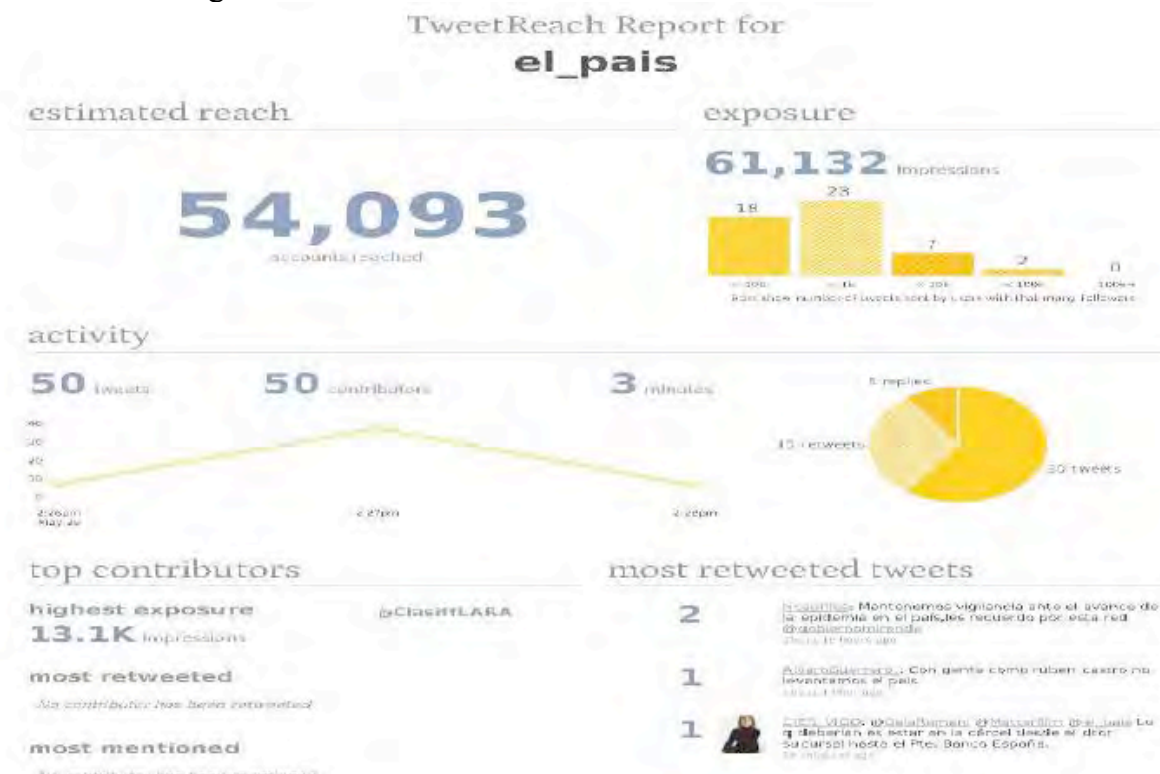

Fuente(s):Tweet Reach, junio 2013.

El seguimiento diario que realizamos durante dicha semana, nos ha permitido hacer el trasladado de los datos obtenidos en la siguiente tabla. 
Tabla 1.2: Tweets elpais.com: 18 a 24 de junio de 2013

\begin{tabular}{|c|c|c|c|c|c|c|}
\hline Fecha & $\begin{array}{c}\text { Número de } \\
\text { tweets }\end{array}$ & $\begin{array}{c}\text { Hastags más } \\
\text { utilizados }\end{array}$ & $\begin{array}{l}\text { Número de } \\
\text { respuestas } \\
\text { a la gente }\end{array}$ & Menciones & $\begin{array}{l}\text { Número } \\
\text { de } \\
\text { retweets } \\
\text { propios }\end{array}$ & $\begin{array}{c}\text { Número } \\
\text { de } \\
\text { retweets } \\
\text { ajenos }\end{array}$ \\
\hline M 18 & 56 & $\begin{array}{l}\text { \#últimahora } \\
\text { \#cataluña } \\
\text { \#sp18j }\end{array}$ & 0 & 9 & 12 & 5.449 \\
\hline X 19 & 60 & $\begin{array}{l}\text { \#últimahora } \\
\text { \#hacienda }\end{array}$ & 0 & 9 & 21 & 5.432 \\
\hline J 20 & 58 & $\begin{array}{l}\text { \#cataluña } \\
\text { \#portada } \\
\text { \#finalacb }\end{array}$ & 0 & 5 & 16 & 6.032 \\
\hline V 21 & 57 & $\begin{array}{l}\text { \#tatgranada } \\
\text { \#madrid } \\
\text { \#religión }\end{array}$ & 0 & 3 & 15 & 4.351 \\
\hline S 22 & 25 & ----- & 0 & 2 & 6 & 1.587 \\
\hline D 23 & 27 & $\begin{array}{l}\text { \#honduras } \\
\text { \#snowden } \\
\text { \#mandela } \\
\text { \#portada }\end{array}$ & 0 & 0 & 3 & 2.801 \\
\hline L 24 & 52 & $\begin{array}{l}\text { \#sudáfrica } \\
\text { \#lospapelesdebárcenas } \\
\text { \#Supermoon }\end{array}$ & 0 & 10 & 10 & 4.937 \\
\hline
\end{tabular}

Fuente: Elaboración propia, 2013.

En cuanto al periódico El País, algunas de las noticias más importantes nos invitan a seguir informándonos no sólo a través del portal digital sino a través de esta red social, para ello nos dan la dirección de la página del diario en Twitter y algunos hashtags con los que llegamos más rápido.

No obstante, cabe destacar la mayor presencia de Eskup, la red social propia -coincidiendo su lanzamiento con el inicio del mundial de fútbol de Sudáfrica de 2010-. El objetivo es ofrecer una red social de carácter abierto donde seguir la información en tiempo real y debatir con los profesionales del periódico las noticias por medio de mensajes cortos que pueden incluir videos, imágenes o enlaces a noticias propias. También interactúa con el resto de redes sociales, dando la opción a los usuarios de compartir la información creada en sus cuentas de Twitter y Facebook. Una vez dado de alta, el usuario de Eskup puede personalizar su red en su perfil, elegir temas o personas que le interesa seguir, y optar por la plataforma que usará principalmente para conectarse a la red. El sistema de mensajes también permite mostrar videos -basta con copiar el enlace en el mensaje-, pero solo aparecerá una muestra reducida del video en los enlaces a Youtube y Vimeo.

En el ámbito digital, Elpaís.com es el líder mundial de los medios españoles, según datos de comScore relativos a diciembre de 2013. Una presencia que no se limita al usuario de ordenador, sino que alcanza al público de todas las plataformas mediante nuevas aplicaciones, lo que ha permitido obtener una audiencia desde dispositivos móviles cercana al $30 \%$. La presencia de El País en las redes sociales ha sido también muy notoria como hemos descrito. Entre los productos específicos en soportes digital, durante 2012 lanzó "El País Selección", que reúne recopilaciones de artículos, reportajes, entrevistas y obras inéditas, disponible para Kindle, el lector de libros electrónicos de Amazon.

\section{Estructura de elpais.com}

El diario El País se vio obligado en 2012 a acometer una fuerte reducción de sus gastos, estas medidas, implicaron cambios organizativos y de producción. Toda la redacción de El País, trabaja, independientemente de la salida de los contenidos -vía edición impresa, ordenadores, móviles o tabletas-, con los 
mismos niveles de calidad y rigor. Los cambios no han impedido que rmedio, en sus versiones impresa y digital, continúe sumando el mayor número de lectores de la prensa española.

Asimismo, en 2012 se concluyó la integración multimedia de la redacción, con el criterio de digital first (es decir, primero la información en el soporte de Internet). Esta integración multimedia no habría sido posible sin el vídeo, y en ese terreno se incluyeron retransmisiones en directo de distintos acontecimientos, tanto actos institucionales, como manifestaciones espontáneas en las calles.

En el nuevo rediseño de su home del 22 de febrero, presenta una navegación más completa. Hay básicamente tres maneras de navegar. En la parte de arriba, a la altura de la cabecera y con código de colores, se encuentra el acceso a las seis principales secciones informativas: Internacional, Política, Economía, Cultura, Sociedad y Deportes. Justo debajo, englobados en el concepto "Está pasando", un enlace a los temas más vivos del día. Y en la columna de la derecha está todo. Absolutamente todas las secciones y sus sub-secciones, los blogs, encuentros, programación de televisión, servicios, edición impresa, las bolsas, clasificados y mucho más. Es el lugar para encontrar lo que se busca.

La portada se estructura de la siguiente manera, en la parte superior se concentra la información diaria, dividida en dos columnas y jerarquizada. En la parte inferior arranca Opinión, con una entrada a cada viñeta, y después los últimos blogs actualizados. El siguiente bloque lo comparten El Viajero y SModa. Le sigue el acceso a los Especiales más destacados, y justo después un espacio para fotografías y vídeos. Y finalmente se cierra con el espacio para suscriptores, donde aparecen las portadas de los productos impresos más destacados de El País.

Toda la información diaria generada por los periodistas del medio se puede encontrar de manera fácil y jerarquizada en la web.

La búsqueda de información, se encuentra encima de la barra de navegación superior, a la derecha. Los resultados aparecen por nivel de coincidencia, aunque también se pueden ordenar por fecha de publicación. Si han sido publicados en la edición impresa aparecen con una cabecera dorada. El segundo sistema de búsqueda, permite ver la evolución de la portada de la web de El País y la de las portadas de las secciones. Y por último, tiene una búsqueda por etiquetas o temas, accesible al final de la barra de navegación del "Está pasando".

Utilizan un sistema de etiquetas, para documentar de manera pública las noticias. Cada información se asocia a una serie de palabras, nombres propios o conceptos que van generando automáticamente diferentes puntos de entrada y enriqueciendo miles de nichos temáticos. Pasamos de un número limitado de secciones coincidentes con las de la edición impresa a un número ilimitado que ayuda a agrupar y a encontrar la información en función de intereses más concretos.

En "Lo más visto" se encuentra las 50 historias más vistas de todo lo publicado en la web, incluyendo blogs, fotos, vídeos y productos especiales como SModa. La medición se actualiza cada hora sobre periodos móviles de 24 horas y mediante un sistema de flechas se puede seguir la evolución de las noticias.

Para poder hacer comentarios, los lectores, es obligatorio registrarse. Todas las noticias, salvo excepciones, están abiertas a comentarios. Para participar es necesario registrarse, dentro de la política de El País de mejorar la calidad de la conversación. Los comentarios que no cumplan las normas de publicación serán retirados. Estar registrado permite guardar en el perfil personal de Eskup (la plataforma social de El País) el histórico de nuestros comentarios, e interactuar con otros lectores y con los periodistas del medio.

\section{El Mundo, el segundo en usuarios}

Anteriormente denominado formalmente "El Mundo del siglo XXI", es otro de los periódicos nacionales que ha tenido que adaptarse a las nuevas tecnologías para fomentar la participación de los lectores y propiciar su fidelización. Este diario cuenta con una herramienta, "Orbyt", de quiosco on-line que permite la suscripción al periódico durante determinados períodos para intentar incrementar sus ventas.

En su página web, ofrece el acceso directo a la edición no sólo española sino también americana, así como las ediciones realizadas para las comunidades autónomas donde este diario se publica. Con este fácil acceso, se permite al usuario la posibilidad de consultar la información que más le 
interesa en cada momento, segmentada por zonas y propone una iniciativa de consulta no sólo de la edición nacional. Los lectores pueden establecer así sus preferencias informativas de una forma rápida y cómoda, todo desde la misma página web.

Para fomentar la participación del ciudadano, "elmundo.es", incluye una sección denominada "Lo +" que contiene los titulares de las noticias más visitadas y, por tanto, de las consideradas más importantes o más llamativas. Este apartado ayuda a conocer rápidamente aquello que tiene una mayor actualidad y relevancia para los lectores y que, por tanto, necesita conocer para saber qué ha sucedido.

A través de los comentarios habilitados en cada noticia fomenta la participación de todos estos lectores que asiduamente consultan el periódico on-line. Igualmente, propone "la portada de los lectores", sección que coloca las noticias en primera plana según los votos que los internautas han dado a cada noticia. Les otorga así la capacidad de poder decidir, de colaborar de una forma activa con el diario y no sentirse como meros lectores. Además de esta forma, también da cabida a los debates entre los usuarios, fomenta la creación de ciudadanos activos para con el diario y les propone una forma diferente de pensar en la información que han leído, comentando sus impresiones con el resto de las personas que estén allí para debatir con ellos.

Como no podía ser de otra manera, la interrelación del medio y el lector también se produce en este caso a través de las redes sociales -Facebook, o Technocrati- donde, la presencia de los periódicos on-line, es ya incontestable. Así como la opción, en redes sociales como Menéame o Delicious, de votar las noticias y realizar una labor de criba de la información menos importante.

Por otro lado, para que sus clientes no pierdan información y estén continuamente actualizados, también ofrece su propio servicio de RSS que proporciona los titulares de la información en el momento en el que se producen y según los intereses establecidos por el usuario registrado en ella.

Tabla 1.3: elmundo.es

\begin{tabular}{|l|l|r|}
\hline \multicolumn{1}{|c|}{ Página web } & \multicolumn{1}{|c|}{ http://www.elmundo.es/ } & \multirow{2}{*}{ Seguidores } \\
\hline Estructura de red social & Sí & \\
\hline $\begin{array}{l}\text { Log In con cuentas de otras redes } \\
\text { sociales }\end{array}$ & No & 125.653 \\
\hline Página/Grupo/Perfil de Facebook & https://www.facebook.com/mundo.es & \\
\hline Perfil de Twitter & @elmundoes & \\
\hline Promoción de artículos en redes & Facebook, Twitter & \\
\hline Gadgets en la web & Twitter, Facebook & \\
\hline Redes sociales complementarias & Tuenti, MySpace, Live Spaces & \\
\hline Agregadores de noticias & Meneame, del.ici.ous, fresqui & \\
\hline Otras consideraciones & $\begin{array}{l}\text { En el perfil de twitter cabe señalar que } \\
\text { los grupos y personas a los que sigue el } \\
\text { diario son, en la mayoría de los casos, } \\
\text { periodistas y personajes reconocidos } \\
\text { dentro del panorama cultural. }\end{array}$ & \\
\hline
\end{tabular}

Fuente: Elaboración propia, 2013.

\section{Presencia en las redes sociales}

Su página de Facebook, con aproximadamente 126.000 seguidores, es actualizado constantemente salvo en el fin de semana, donde disminuye de manera considerable la actividad- por publicaciones que incluyen, además de títulos y pequeñas entradillas, vídeos y fotografías que dan veracidad a la información que publican. Además esta información va delimitada por la sección a la que pertenece la información, para facilitar la búsqueda de algo en concreto si se precisara y añaden la dirección web de la noticia en cuestión, por si nos interesa a grosso modo, poder acceder a ella para leer el contenido completo de la misma.

Todos los días, publican en Facebook la portada de la edición impresa, salvo la de los fines de semana. También hacen preguntas para que la gente opine, a través de las noticias que van generando constantemente. La participación de la gente es bastante amplia -hemos encontrado noticias con 
más de 80 comentarios- pero sin duda donde más participación hay son en los temas de la crisis financiera española, política y deportes.

Utiliza Twitter como red social de lanzadera de noticias que le sirve para promocionar sus propios contenidos, está continuamente actualizándolos, menos el fin de semana que disminuye notablemente y solo utiliza el microblogging para las noticias más relevantes. Usando los tuits como pequeños titulares sobre las noticias que lanzan, poniendo un enlace a continuación que te redirecciona a la página del medio para que puedas ver la noticia de forma extensa, muchos de ellos e incluso a galerías de imágenes donde podemos encontrar el soporte gráfico de la noticia en cuestión. Sus tweets hacen referencia a las noticias de última hora, por lo que a cada minuto aparecen nuevos avisos en su tablón. Avisos que a su vez se expondrán en los Time-Line de las personas que sigan esta cuenta. También utiliza el etiquetado de contenidos, de tal forma que cualquiera que ponga una etiqueta en su tuit, el lector pueda ver todos los mensajes que se hayan escrito sobre ese tema. Las que más utiliza suelen ser: \#ultimahora, para temas que acaban de acontecer y \#endirecto, normalmente para temas que está cubriendo el medio en ese momento, es muy alto contenido de deportes, sobre todo los días de partido de fútbol, donde se acentúan con notoriedad tanto los tuits del propio medio como los retuits que éste hace de los seguidores que tiene-. Además, suelen etiquetar también a personas que trabajan dentro del propio medio o periodistas de relevancia que se puedan sentir atraídos por el contenido del tuit.

El número de seguidores, en Twiter es de 1.150.589, entre sus seguidores, encontramos desde gente anónima a periodistas y grandes comunicadores, representantes del medio, personalidades famosas, etc.-, pertenecen a 59 países y 430 ciudades. (sus intereses son Director, Marketing, Social Media, Digital). El número de perfiles seguidos por El Mundo es de 319. El número de tweets diario ronda los 18 y 2.395 retweets por 100 tweets. Su perfil tiene una media de 102 respuestas por 100 tweets, pero para tratarse de un medio de información generalista atado al acontecer de la actualidad que sucede diariamente, parece una referencia buena.

En el seguimiento que hicimos durante la semana -del 18 al 24 de junio- a través de "Tweet Reach" nos permitió medir el alcance que tuvo la cuenta de Twitter, las observaciones realizadas mediante intervalos de cinco minutos, nos dio unos 28 tweets publicados por el medio, con 18 retweets y 4 comentarios. Alcance estimado de 55.493, la exposición, (impresiones) 69.971.

Figura 2: Datos seguimiento Tweet Reach

TweetReach Report for

elmundo.es

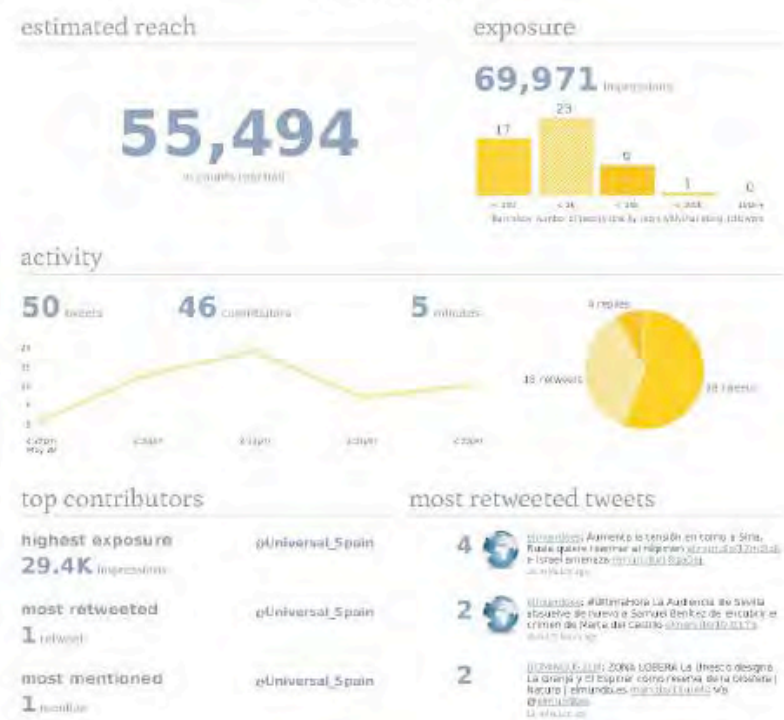

Fuente(s):Tweet Reach, junio 2013. 
El seguimiento diario que realizamos durante dicha semana, nos ha permitido hacer el trasladado de los datos obtenidos en la siguiente tabla.

Tabla 1.3: Tweets elmundo.es: 18 a 24 de junio de 2013

\begin{tabular}{|c|c|c|c|c|c|c|}
\hline $\begin{array}{l}\mathrm{Fe}- \\
\text { cha }\end{array}$ & $\begin{array}{l}\text { Número } \\
\text { de tweets }\end{array}$ & $\begin{array}{c}\text { Hastags más } \\
\text { utilizados }\end{array}$ & $\begin{array}{l}\text { Número de } \\
\text { respuestas a } \\
\text { la gente }\end{array}$ & $\begin{array}{c}\text { Mencio- } \\
\text { nes }\end{array}$ & $\begin{array}{l}\text { Número de } \\
\text { retweets } \\
\text { propios }\end{array}$ & $\begin{array}{l}\text { Número de } \\
\text { retweets } \\
\text { ajenos }\end{array}$ \\
\hline 18 & 42 & $\begin{array}{l}\text { \#últimahora } \\
\text { \#encuentrodigi- } \\
\text { tal } \\
\text { \#endirecto }\end{array}$ & 0 & 0 & 2 & 1.305 \\
\hline 19 & 47 & $\begin{array}{l}\text { \#últimahora } \\
\text { \#ampliamos } \\
\text { \#afterearth }\end{array}$ & 0 & 0 & 6 & 2.439 \\
\hline 20 & 42 & $\begin{array}{l}\text { \#últimahora } \\
\text { \#encuentrodigi- } \\
\text { tal } \\
\text { \#adiosgaldofini }\end{array}$ & 0 & 0 & 3 & 1.208 \\
\hline 21 & 35 & $\begin{array}{l}\text { \#endirecto } \\
\text { \#últimahora }\end{array}$ & 0 & 0 & 5 & 697 \\
\hline 22 & 32 & --- & 0 & 0 & 0 & 911 \\
\hline 23 & 37 & ---- & 0 & 0 & 0 & 855 \\
\hline 24 & 48 & $\begin{array}{l}\text { \#últimahora } \\
\text { \#ampliamos } \\
\text { \#envivo } \\
\text { \#participación } \\
\text { \#tuitopina } \\
\text { \#endirecto }\end{array}$ & 0 & 4 & 2 & 1.486 \\
\hline
\end{tabular}

Fuente: Elaboración propia, 2013.

A la vez, cabe destacar que El Mundo utiliza de esta red para publicar la mayoría de sus informaciones del medio on-line. Si comparamos y cotejamos ambas webs, observaremos un alto grado de coincidencia entre lo publicado en Twitter y lo publicado en la edición online, no ofreciendo así algo que diferencie contenidos.

\section{Estructura de elmundo.es}

Coincidiendo con el inicio del año 2009, (su vigésimo aniversario), este periódico fue el primero en llevar a cabo el relanzamiento integral de una marca: edición impresa, digital, así como sus revistas. En pasado 5 de noviembre de 2013, se mostraba a los usuarios el último rediseño de Elmundo.es con la misma filosofía, el firme compromiso con la información, bajo una nueva óptica. Lo primero y más importante que hay que destacar, es que El Mundo se ha convertido en una web de pago. Enlaza todas las noticias disponibles en el periódico el mismo día, pero aplica un límite de consultas gratuitas que se pueden realizar desde la misma IP. Son 20 los artículos que se puedan consultar de forma gratuita cada mes. A partir de entonces, para disfrutar de un acceso ilimitado a la web, el lector deberá pagar 4,99 euros mensuales ( 0,99 en promoción los primeros tres meses).

En cuanto a lo estrictamente visual, el principal en la home de la nueva página, fue la claridad organizativa de los elementos. Rediseño de la cabecera, nueva organización de la navegación principal y secundaria, la columna central, gana más espacio.

La página utiliza tres columnas de inicio, cuyo espacio luego se divide para ofrecer dos nuevas columnas, una de ellas en pequeño tamaño. Bloques de contenido diferenciados gráficamente más allá de la diferenciación de secciones y uso de colores para distintas temáticas, priman los azules y grises. 
La tercera columna (la dispuesta más a la derecha) se utiliza para disponer todas las secciones, o para ofrecer servicios como la meteorología, la guía de TV o la bolsa.

La disposición de las secciones en la página principal va variando en función de la importancia de las noticias, pero el mayor peso que se dio fue a las páginas de opinión (por encima de la sección deportiva), que antes no aparecía en la web.

Los artículos se desarrollan en un formato mucho más claro y uniforme, con una evidente ausencia de elementos distractivos, pero cuya disposición desaprovecha un porcentaje de la página muy importante, haciéndola innecesariamente vertical y larga.

La barra "Es noticia". La influencia Trending Topic también llega a la home de El Mundo, con el uso de la ya típica barra de tags con los temas del día.

Uno de los aspectos que llama la atención es que no hay una actualización de contenidos tan frenética como en el anterior diseño. Prácticamente a la hora de redacción de este artículo (las 11 de la mañana) tiene las mismas noticias destacadas que en la noche de su estreno (a las 2 de la madrugada).

Para facilitar el acceso a la información, ofrece dos herramientas; por un lado una sección en la que con un solo clic se puede acceder rápidamente a las noticias publicadas 24, 48 ó 72 horas antes; y, para búsquedas más antiguas, cuenta con una hemeroteca digitalizada en la que puede filtrarse la búsqueda por día, mes y año. Y, una vez establecida la fecha concreta, puede incluso elegirse la edición que quiere consultarse. También puede realizarse una búsqueda sobre temas introduciendo las palabras clave que se desean encontrar y aparecerán todas las noticias relacionadas con ella independientemente de la fecha.

\section{Conclusiones}

Según el último barómetro publicado por GAD3, el IV Informe 2013: Medios de Comunicación en Redes Sociales:

- Dentro de la prensa generalista, el medio con más seguidores en redes sociales, es El País con un total más de 3 millones, un $77 \%$ más que en el año 2012 y con un $90 \%$ de seguimiento vía Twitter. El Mundo ocupa el segundo lugar con casi 1,3 millones.

- Los últimos datos recogidos en relación a la presencia de los medios en redes sociales son de 56 medios en España, de los cuales se analizaron las redes sociales de Facebook, Twitter y Youtube por ser las plataformas con mayor influencia digital.

- Twitter es la red social más seguida con casi 13 millones de seguidores en los principales medios de comunicación, lo que supone un $80 \%$ más que en 2012 . Le sigue Facebook $(7,5$ millones de usuarios) mientras que Youtube ha incrementado sus suscriptores en un $139 \%$.

- La prensa exclusivamente digital ha superado el umbral de los 2,5 millones de seguidores, sobre todo con ayuda de Twitter y a la aparición de más medios exclusivamente digitales.

Después de los análisis realizados en este estudio, podemos comprobar como ambos medios, los más fuertes y con más seguidores de los medios generalistas en los cibermedios españoles, presentan similitudes y algunas diferencias.

Ambos medios se benefician de este uso de las redes sociales y en cada uno de sus perfiles presentan similitudes en cuanto a: seguidores, perfil de profesional o noticias a publicar.

Sin embargo, haciendo una comparativa de ambos perfiles de estos medios impresos adaptados al medio digital a través de redes sociales, podemos observar como El Mundo está presente en Twitter un año menos que El País, pero ha conseguido abarcar más países y ciudades en el mundo.

Por el contrario El Mundo, publicando menos tweets al día que El País, consigue una mayor participación por parte de los usuarios y manejo de herramientas que le permiten ampliar su información.

El País en cambio, sigue en la línea de tener los mayores seguidores y respuestas activas por parte de los seguidores y usuarios, debido a la sincronización de la versión impresa, la versión digital y las diferentes redes sociales que utiliza.

Aunque los dos medios proyectan su marca, hacia las plataformas de redes sociales ya existentes, como Facebook y Twitter, El País, ha creado un espacio de comunidad o red social (Eskup) dentro de la propia web del medio con el objetivo de atraer lectores que formen parte de un grupo de 
personas vinculado al propio diario, dando la posibilidad de crea una identidad digital que le permite comentar noticias, enviar notas o, incluso, tener su propio blog.

Los medios están presentes en Twitter y utilizan sus cuentas diariamente, aunque la frecuencia varía considerablemente de manera aleatoria. Las horas en las que los medios más utilizan Twitter es por las mañanas y para ampliar información de última hora a grandes rasgos. 


\section{REFERENCIAS}

Cabrera, M. Á. (coordinadora) (2013). Evolución de los cibermedios. De la convergencia digital a la distribución multiplataforma. Madrid: Editorial Fragua.

Carballar Falcón, J. A. (2011). Twitter: marketing personal y profesional. Madrid: RC libros.

Eskup. http://eskup.elpais.com/Estaticas/ayuda/quees.html (Consultado el 27 de enero de 2014)

García Estévez, N. (2012). Redes sociales en internet. Implicaciones y consecuencias de las plataformas 2.0 en la sociedad. Madrid: Editorial Universitas.

Informe anual PRISA 2013. http://www.prisa.com/informe-anual-2013/ (Consultado el 13 de enero de 2014)

IV Informe GAD3: Medios de Comunicación en Redes Sociales 2013. http://www.slideshare.net/GAD3_com/4-informe-de-medios-en-redes-2013-de-gad3 (Consultado el 5 de enero de 2014)

López García, G. (2005). Modelos de comunicación en Internet. Valencia: Editorial Tirant Lo Blanc.

Orihuela, J.L. (2011). Mundo Twitter: una guía para comprender y dominar la plataforma que cambió la red. Barcelona,: Editorial Alienta.

Rissoan R. (2011). Redes sociales. Facebook, Twitter, inkedin y Viadeo en el mundo profesional. Barcelona: Editorial Eni.

Salgado Santamaría, C. y Zamarra López, M. M. (2012). Sinergias periodísticas en las redes sociales, los medios audiovisuales y la prensa digital. En: Innovaciones periodísticas en las redes sociales (pp. 39-65). Madrid: Servicio de Publicaciones de la Universidad Complutense de Madrid.

Zamarra López, M. M. (2010). Los entornos de las Redes Sociales en España. En J. M. Flores Vivar (dir.), Reinventar el periodismo y los medios. Apuntes sobre el Estado del Arte en la construcción del ciberperiodismo (pp. 133-142). Madrid: Editorial Fragua.

\section{SOBRE LA AUTORA}

Mercedes Zamarra: Doctora en Ciencias de la Información (Universidad Complutense de Madrid)en 1996. Profesora del Dpto. de Periodismo II desde 1999-2000. Miembro del grupo de investigación Cybermedia II: Desarrollos e Innovaciones del Periodismo en las Redes Sociales, en Internet y Telefonía Móvil. Convergencias, Modelos de Negocios, Servicio y Formación (Ref. CSO2011-25235)" (Plan Nacional de I+D-i 2012-2014, anteriormente también formó parte del grupo de investigaciónCYBERMEDIA: Innovaciones, procesos y nuevos desarrollos del periodismo en Internet, telefonía móvil y otras tecnologías del conocimiento MINISTERIO DE EDUCACIÓN Y CIENCIA. (Plan Nacional de I+D+i 2007-2009). Además soy miembro de un grupo de investigación UCM, donde se abordan líneas de investigación en el contexto general de la Comunicación Social, dentro de la parcela específica del análisis de contenidos, centradas en la aplicación de las nuevas tecnologías en los medios de comunicación impresos y digitales. 